University of Nebraska - Lincoln

DigitalCommons@University of Nebraska - Lincoln

US Department of Energy Publications

U.S. Department of Energy

2009

\title{
Fullerene-Encapsulated Atoms in the Light of Synchrotron Radiation
}

A. M. Müller

Institut für Atom-und Molekülphysik

S. Schippers

Institut für Atom-und Molekülphysik

D. Esteves

Lawrence Berkeley National Laboratory

M. Habibi

University of Nevada - Reno

R. A. Phaneuf

University of Nevada - Reno, phaneuf@unr.edu

See next page for additional authors

Follow this and additional works at: https://digitalcommons.unl.edu/usdoepub

Part of the Bioresource and Agricultural Engineering Commons

Müller, A. M.; Schippers, S.; Esteves, D.; Habibi, M.; Phaneuf, R. A.; Kilcoyne, A. L. D.; Aguilar, A.; and Dunsch, L., "Fullerene-Encapsulated Atoms in the Light of Synchrotron Radiation" (2009). US Department of Energy Publications. 338.

https://digitalcommons.unl.edu/usdoepub/338

This Article is brought to you for free and open access by the U.S. Department of Energy at DigitalCommons@University of Nebraska - Lincoln. It has been accepted for inclusion in US Department of Energy Publications by an authorized administrator of DigitalCommons@University of Nebraska - Lincoln. 


\section{Authors}

A. M. Müller, S. Schippers, D. Esteves, M. Habibi, R. A. Phaneuf, A. L. D. Kilcoyne, A. Aguilar, and L. Dunsch 


\title{
Fullerene-Encapsulated Atoms in the Light of Synchrotron Radiation
}

\author{
A. Müller*, S. Schippers*, D. Esteves ${ }^{\dagger, * *}$, M. Habibi ${ }^{\dagger}$, R. A. Phaneuf ${ }^{\dagger}$, \\ A. L. D. Kilcoyne**, A. Aguilar** and L. Dunsch ${ }^{*}$ \\ *Institut für Atom- und Molekülphysik, Justus-Liebig-Universität, 35392 Giessen, Germany \\ ${ }^{\dagger}$ Department of Physics, MS 220, University of Nevada, Reno, NV 89557-0058 \\ ${ }^{* *}$ Advanced Light Source, Lawrence Berkeley National Laboratory, MS 7-100, Berkeley, CA 94720 \\ ${ }^{\ddagger}$ Leibniz-Institut für Festkörper- und Werkstoffforschung Dresden, D-01171 Dresden, Germany
}

\begin{abstract}
Mass-selected beams of endohedral fullerene $\mathrm{Ce} @ \mathrm{C}_{82}^{+}$ions, of atomic $\mathrm{Ce}^{q+}$ ions $(q=2,3,4)$, and of empty fullerene-cage $\mathrm{C}_{82}^{+}$ions were employed to study photoionization of fullerene-encapsulated and free cerium atoms. The $\mathrm{Ce} 4 \mathrm{~d}$ inner-shell contributions to single and

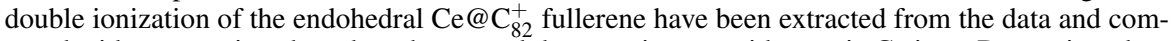
pared with expectations based on theory and the experiments with atomic Ce ions. Dramatic reduction and redistribution of the ionization contributions to $\mathrm{Ce} 4 \mathrm{~d}$ photoabsorption is observed. More than half of the Ce $4 \mathrm{~d}$ oscillator strength is apparently diverted to additional decay channels of the $\mathrm{Ce} @ \mathrm{C}_{82}^{+}$complex.
\end{abstract}

Keywords: atoms in a box, decay of encapsulated excited atoms, redistribution of oscillator strength, giant resonances, plasmons

PACS: $32.80 . \mathrm{Fb}, 33.80 .-\mathrm{b}, 33.80 . \mathrm{Eh}, 36.40 .-\mathrm{c}$

\section{INTRODUCTION}

Several years after the discovery of $\mathrm{C}_{60}$ by Kroto et al. [1] the same team [2] demonstrated the production of endohedral La@ $\mathrm{C}_{82}$ with the La atom encapsulated inside the $\mathrm{C}_{82}$ fullerene. Since then, the concept of an atom inside a fullerene molecule has fascinated chemists and physicists alike. Endohedral fullerenes [3] have stimulated the imaginations of researchers from many different fields concerning what could happen to an atom in the unique environment of a carbon cage. New possibilities for applications in nanostructure science and technology are being vigorously explored. For example, confinement within a fullerene could have some unique advantages in isolating an atom from its environment, thereby providing a building block for the qubits of a quantum computer $[4,5]$. The chemical isolation of reactive and poisonous atoms may also open up new possibilities in medical imaging and cancer therapy [6, 7].

Numerous theoretical studies have explored the response of atoms encapsulated in fullerene cages to ionizing electromagnetic radiation. A review of photoionization of atoms encaged in spherical fullerenes has recently been written by Dolmatov [8], illuminating theoretical models and calculated results. In contrast to the substantial number of theory papers that has been accumulated especially over the last several years, publications on experiments with free endohedral molecules in the gas phase are extremely sparse. Measurements are almost prohibitively difficult. Challenges include the availability of sufficient amounts of target material for gas phase experiments and the purity

CP1197, The Fourth International Symposium on Atomic Cluster Collisions (ISACC 2009), edited by A. V. Solov'yov and E. Surdutovich

(c) 2009 American Institute of Physics 978-0-7354-0734-3/09/\$25.00 
of the samples to be investigated. Obtaining absolute cross sections for interactions of endohedral species with any kind of radiation is presently close to impossible. A few gas phase experiments with neutral endohedral fullerenes were conducted by Mitsuke and coworkers on Ce@ $\mathrm{C}_{82}$ [9], Dy@ $\mathrm{C}_{82}$ [10] and Pr@ $\mathrm{C}_{82}$ [11] exposed to synchrotron light. Cross sections for photoionization with different exit channels have been inferred and evidence was claimed for oscillations as predicted in the $4 \mathrm{~d}-4 \mathrm{f}$ atomic inner-shell contributions to photoionization of $\mathrm{Xe} @ \mathrm{C}_{60}$ [12]. Difficulties in these experiments were the determination of the density and purity of the vapor targets of the endohedral fullerene species. Large statistical and systematic error bars limited the possibility of definitive conclusions.

A different experimental approach was chosen in the present studies [13, 14] to overcome problems with the characterization of the endohedral fullerene target and with quantifying its properties. The present paper provides a brief overview of the work that has been carried out on photoionizartion of $\mathrm{Ce} @ \mathrm{C}_{82}^{+}$using the technique of merged beams of photons and endohedral fullerene ions.

\section{EXPERIMENT}

The availability and sufficient quantities of the endohedral fullerenes are a very serious problem. Efficient production and purification processes of the endohedral fullerenes [3] are essential and had to be combined in the present measurements with high ion yield from dilute vapors $\left(\sim 10^{-6} \mathrm{hPa}\right)$, high detection probabilities (close to $\left.100 \%\right)$ and advanced measures to provide low levels of detector background [13]. For the production of $\mathrm{Ce} @ \mathrm{C}_{82}$, cerium fullerene soot was prepared by a standard arc burning process [15]. Given the mass separation capability of the photoionization experiment and the effort required for producing endohedral materials, the purification process [16] was limited to the $20 \%$ level of the predominant $\mathrm{Ce} @ \mathrm{C}_{82}$ component in order to maximize the output of the desired material. Milligram quantities of endohedral $\mathrm{Ce} @ \mathrm{C}_{82}$ fullerenes were sufficient to provide picoAmpere ion currents continuously over several days.

For the present experiments the photon-ion merged beams endstation [17] of the undulator beamline 10.0.1 of the Advanced Light Source (ALS) was employed. For the production of $\mathrm{Ce} @ \mathrm{C}_{82}^{+}$ion beams the endohedral fullerene powder is evaporated and efficiently ionized in a low-power plasma of an electron cyclotron resonance (ECR) ion source. The ions are extracted and accelerated by several $\mathrm{kV}$ thus forming a beam with defined particle energies. Mass selection by a subsequent dipole magnet provides the desired ion species in the form of a well characterized fullerene ion beam. The potential of the magnet spectrometer is demonstrated by the mass spectrum shown in Fig. 1.

The mass/charge selected ion beam serves as the target for a beam of synchrotron radiation in a merged beam geometry. The merged-beams technique for photon-ion interactions is well established [18] and can provide absolute cross sections taking advantage of the availability of energetic projectile and target beams in the experiments. Density profiles and intensities are readily measured for such beams and complete registration of product ions in a suitable detector can be ensured [17]. Different product ion beams are dispersed by a second dipole analyzing magnet and a subsequent electrostatic spherical $90^{\circ}$ deflector. Thereby the product ions are sorted with respect to their energy, mass and 


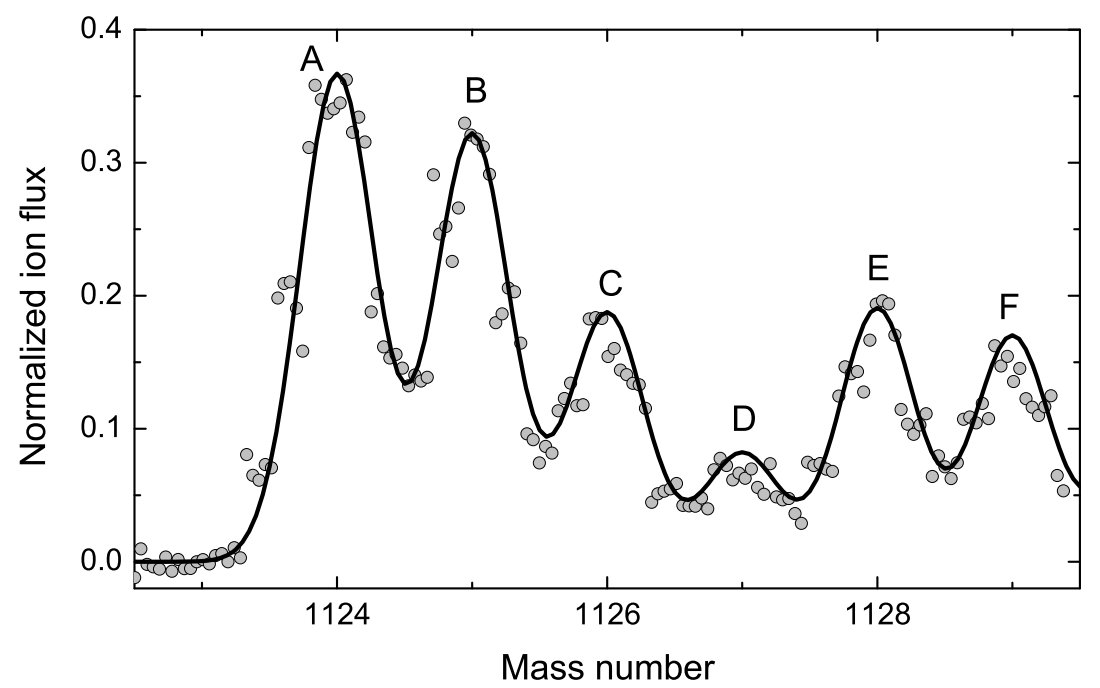

FIGURE 1. Mass spectrum of a mixed beam of $\mathrm{Ce} @ \mathrm{C}_{82}^{+}$and $\mathrm{C}_{94}^{+}$ions obtained with the magnet spectrometer that is used to select the target ion beams for the photon-ion merged-beam experiments. The mass resolution chosen for this measurement was approximately 1700. Measured ion currents are indicated by the shaded circles. The solid line is a simulation of the data assuming a $31 \%$ admixture of $\mathrm{C}_{94}^{+}$in the ion beam and a distribution of isotopologues as expected from combinatorial probabilities based on the natural abundances of ${ }^{12} \mathrm{C},{ }^{13} \mathrm{C},{ }^{140} \mathrm{Ce}$, and ${ }^{142} \mathrm{Ce}$. The different peaks are (A) ${ }^{140} \mathrm{Ce} @{ }^{12} \mathrm{C}_{82}^{+}$, (B) ${ }^{140} \mathrm{Ce} @{ }^{13} \mathrm{C}_{1}{ }^{12} \mathrm{C}_{81}^{+}$, (C) ${ }^{140} \mathrm{Ce} @{ }^{13} \mathrm{C}_{2}{ }^{12} \mathrm{C}_{80}^{+}+{ }^{142} \mathrm{Ce} @{ }^{12} \mathrm{C}_{82}^{+}$, (D) ${ }^{140} \mathrm{Ce} @{ }^{13} \mathrm{C}_{3}{ }^{12} \mathrm{C}_{79}^{+}+{ }^{142} \mathrm{Ce} @{ }^{13} \mathrm{C}_{1}{ }^{12} \mathrm{C}_{81}^{+}$, (E) ${ }^{140} \mathrm{Ce} @{ }^{13} \mathrm{C}_{4}{ }^{12} \mathrm{C}_{78}^{+}+{ }^{142} \mathrm{Ce} @{ }^{13} \mathrm{C}_{2}{ }^{12} \mathrm{C}_{80}^{+}+{ }^{12} \mathrm{C}_{94}^{+}$, and (F) ${ }^{140} \mathrm{Ce} @{ }^{13} \mathrm{C}_{5}{ }^{12} \mathrm{C}_{77}^{+}+{ }^{142} \mathrm{Ce} @{ }^{13} \mathrm{C}_{3}{ }^{12} \mathrm{C}_{79}^{+}+$ ${ }^{13} \mathrm{C}_{1}{ }^{12} \mathrm{C}_{93}^{+}$.

charge state. By using merged beams, many systematic problems with measurements on static neutral endohedral species can be avoided.

The goal of the present experiment was to investigate possible differences in the behaviour of free and of caged atomic ions exposed to monochromatic ultraviolet radiation. In particular, the decay of $4 \mathrm{~d}$ vacancies in the encapsulated cerium is the focus of the present study, relating to theoretical considerations recently summarized by Dolmatov [8]. For the purpose of comparison, cross sections for single and double photoionization of $\mathrm{Ce} @ \mathrm{C}_{82}^{+}, \mathrm{C}_{82}^{+}$as well as of $\mathrm{Ce}^{2+}, \mathrm{Ce}^{3+}$, and $\mathrm{Ce}^{4+}$ ions were determined.

\section{RESULTS}

One of the first questions to be answered when studying metal atoms encapsulated within a fullerene is that of the valence state of the atom in the reductive environment of the cage. This has been investigated previously both in theory and experiment leaving little

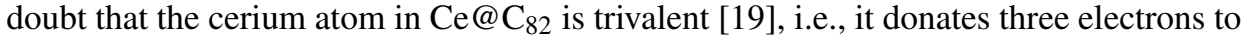
the carbon cage. As a result, the endohedral fullerene, although electrically neutral as a 
whole, can be described as $\mathrm{Ce}^{3+} @ \mathrm{C}_{82}^{3-}$. A recent density functional study [20] explains details of the charge transfer from and to the different subshells of the cerium atom within $\mathrm{Ce} @ \mathrm{C}_{82}$ and provides an explanation to the preferential Ce off-center bonding site on the inner surface of the carbon sphere. Since the present object of investigation is the singly charged $\mathrm{Ce} @ \mathrm{C}_{82}^{+}$ion, the effective charge state of the encaged $\mathrm{Ce}$ atom might be higher than $q=+3$. Therefore, several charge states of atomic Ce were included in this study. Photoionization of Ce atoms and low charge ions is dominated by resonance features associated with excitation of the $4 \mathrm{~d}$ shell [18]. Modification of the cross section of the $\mathrm{Ce} @ \mathrm{C}_{82}^{+}$ion by the encapsulated $\mathrm{Ce}$ atom is to be expected, especially in the energy region of $4 \mathrm{~d} \rightarrow \mathrm{nl}$ resonances. The photon energy range covered in the experiments was between $17 \mathrm{eV}$ and about $190 \mathrm{eV}$ depending on the observable signals. Photon energy spreads were below $0.5 \mathrm{eV}$. Special attention was devoted to the energy range $80 \mathrm{eV}$ to $190 \mathrm{eV}$ where the $4 \mathrm{~d}$ spectral fingerprints of cerium occur.

In the present study the experimental data were normalized to scaled photoionization cross sections for $\mathrm{C}_{60}^{+}$ions obtained with the identical apparatus [21]. At energies from about $50 \mathrm{eV}$ up to the carbon $\mathrm{K}$-shell threshold the measurements for single ionization of $\mathrm{C}_{60}^{+}$ions are found [14] to have an energy dependence as predicted by the Henke model [22] where the photoabsorption of a molecule is just given by the sum of the cross sections for each single atom in the molecule. For $\mathrm{C}_{60}$ this implies 60 times the absorption of a carbon atom. The cross sections found for single ionization of $\mathrm{C}_{60}^{+}$are $12 \%$ below the absorption cross section predicted by the model calculation. Previous experiments with higher fullerenes [14] agreed with the prediction that cross sections of empty fullerenes scale with the number of carbon atoms. Hence, the expected cross section for the empty $\mathrm{C}_{82}$ is $82 / 60$ times that of $\mathrm{C}_{60}$ and accordingly, the measured yields for single ionization of $\mathrm{C}_{82}^{+}$and of $\mathrm{Ce} @ \mathrm{C}_{82}^{+}$were normalized to the expectation in the energy range 80 to $100 \mathrm{eV}$ where cerium does not significantly contribute. Much care was taken to measure the ratios of double versus single ionization cross sections for both the endohedral and the empty fullerene ion, thus providing the basis for normalizing the double ionization yields to the scaled $\mathrm{C}_{60}^{+}$results.

Figure 2 shows the cross section for photo-double ionization of $\mathrm{Ce} @ \mathrm{C}_{82}^{+}$ions. The cross section is enhanced over that of the empty $\mathrm{C}_{82}^{+}$fullerene at energies around $130 \mathrm{eV}$, i.e., in the region where $4 \mathrm{~d}$ excitation of the encapsulated cerium atom can happen. The excess cross section resulting from the presence of the $\mathrm{Ce}$ atom can be obtained by subtracting from the measured data the smooth "background" resulting from the ionization of the empty fullerene. This background can be represented by the dotted line in Fig. 2. For clarification of the valency of the $\mathrm{Ce}$ atom residing within the $\mathrm{Ce} @ \mathrm{C}_{82}^{+}$ion, data obtained for single ionization of atomic $\mathrm{Ce}^{2+}, \mathrm{Ce}^{3+}$ and $\mathrm{Ce}^{4+}$ [23] were compared with the $\mathrm{Ce} 4 \mathrm{~d}$ excess cross section in single ionization of the endohedral $\mathrm{Ce} @ \mathrm{C}_{82}^{+}$ ions. The excess cross section is relatively structureless indicating the hybridization of the outer levels of the $\mathrm{Ce}$ atom and the fullerene cage and the resulting increase of resonance widths. In spite of this difference, the comparison clearly shows the best match of resonance energies for the endohedral $\mathrm{Ce}$ atom with the cross section $\sigma_{3,4}$ for single ionization of atomic $\mathrm{Ce}^{3+}$ (resulting in the production of $\mathrm{Ce}^{4+}$ ). A similar comparison of the excess contribution to the cross section for double photoionization of the endohedral $\mathrm{Ce} @ \mathrm{C}_{82}^{+}$with the cross sections for double photoionization of atomic 


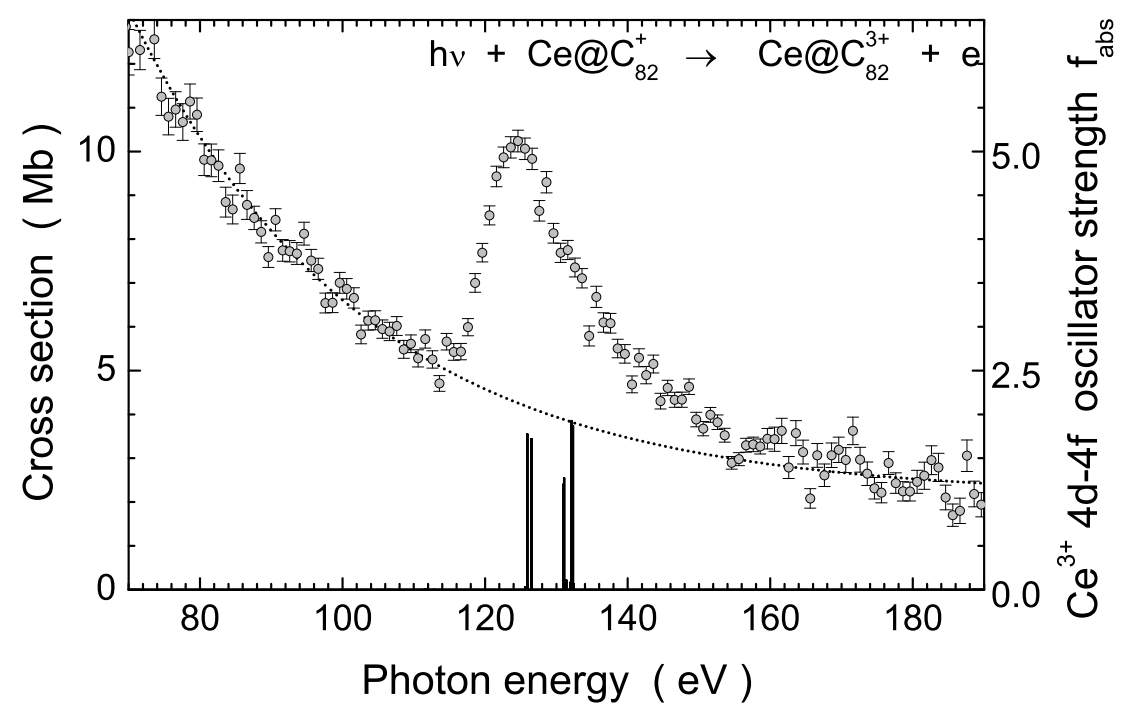

FIGURE 2. Cross sections $\sigma_{1,3}$ for photo-double ionization of $\mathrm{Ce} @ \mathrm{C}_{82}^{+}$. The experimental data are the shaded circles with statistical error bars. The dotted line is a fit curve representing the "empty-fullerene background" under the Ce $4 \mathrm{~d}$ contribution to double ionization of $\mathrm{Ce} @ \mathrm{C}_{82}^{+}$. The vertical bars correspond to the scale on the right and show the distribution of oscillator strengths for absorption by $4 \mathrm{~d}-4 \mathrm{f}$ transitions in $\mathrm{Ce}^{3+}$, calculated by using the Los Alamos Atomic Physics Codes Package [24].

$\mathrm{Ce}^{q+}$ ions gives the best match again for $q=3$. Also the theoretical oscillator strengths for $4 \mathrm{~d}$ photoabsorption by $\mathrm{Ce}^{3+}$ shown in Fig. 2 agree in energy with the observed cross section contribution of the encapsulated Ce atom. As in the neutral $\mathrm{Ce} @ \mathrm{C}_{82}$ molecule the valency of $\mathrm{Ce}$ in the $\mathrm{Ce} @ \mathrm{C}_{82}^{+}$ion is apparently 3, i.e., the investigated endohedral species might be viewed as a $\mathrm{Ce}^{3+} @ \mathrm{C}_{82}^{2-}$ ion.

For atomic $\mathrm{Ce}^{3+}$ ions, photoabsorption in the present energy range is expected to be dominated by $4 \mathrm{~d}$-shell excitations resulting in single and double ionization of the absorbing ion. Triple ionization with a threshold near $180 \mathrm{eV}$ is energetically not allowed and radiative stabilization of a $4 \mathrm{~d}$ vacancy can be neglected. On that basis one would expect a total oscillator strength $f_{a}$ of 10 for the absorption by ten $4 \mathrm{~d}$ electrons. Integration of the cross section sum $\sigma_{3,4}+\sigma_{3,5}$ for $\mathrm{Ce}^{3+}$ ions in the energy range 100 to $170 \mathrm{eV}$ yields $f_{a}=8.5$ [23]. With the limitation of the integration range, a possible small contribution of fluorescence stabilization and the expected total uncertainty of the ionization cross sections for atomic $\mathrm{Ce}^{3+}$ of at least $20 \%$, the total experimental oscillator strength is in good agreement with the expectation. A calculation of oscillator strengths for $4 \mathrm{~d}$ excitations of $\mathrm{Ce}^{3+}$ using the Los Alamos Atomic Physics Codes Package [24] results in an overall sum of $f_{a}=10.44$ (see Fig. 2) with $97 \%$ originating from $4 \mathrm{~d} \rightarrow 4 \mathrm{f}$ excitations. In strong contrast to that, absorption by the encapsulated Ce atom involving $4 \mathrm{~d}$ excitation and subsequent pure single and double ionization of the $\mathrm{Ce} @ \mathrm{C}_{82}^{+}$complex is much smaller. Integration of the excess cross section data for single and double ion- 


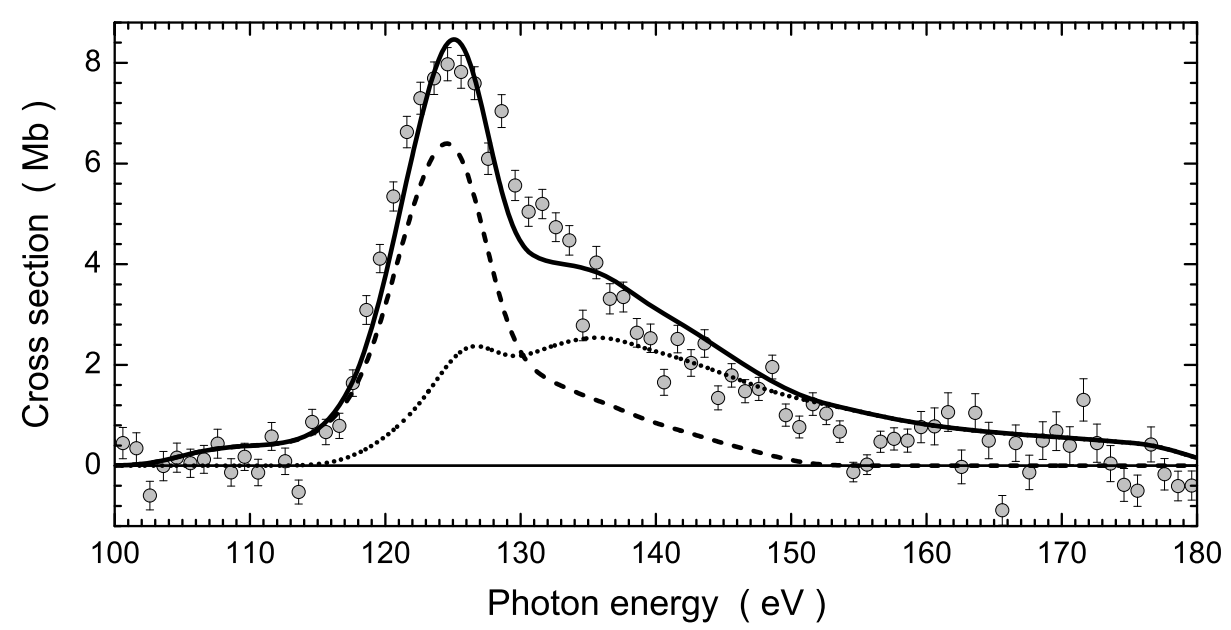

FIGURE 3. Cross section (shaded circles with statistical error bars) for the Ce $4 d$ contribution to double ionization of $\mathrm{Ce} @ \mathrm{C}_{82}^{+}$obtained by subtracting the curve represented by the dotted line from the experimental data shown in Fig. 2. The dashed curve is the cross section $\sigma_{3,4}$ for atomic $\mathrm{Ce}^{3+}$ convoluted with a 5-eV gaussian and multiplied by a factor 0.15 , the dotted curve is the cross section $\sigma_{3,5}$ for atomic $\mathrm{Ce}^{3+}$ convoluted with a $5-\mathrm{eV}$ gaussian and multiplied by a factor 0.22 . The solid line is the sum of the two latter curves.

ization of the endohedral fullerene to $180 \mathrm{eV}$ results in $f_{a}=3.6$, i.e., only $36 \%$ of the expected total oscillator strength $f_{a}=10$ or $42 \%$ of the number observed in photoionization of $\mathrm{Ce}^{3+}\left(f_{a}=8.5\right)$. The missing strength cannot be explained by uncertainties in the normalization procedures used here. Apparently, $4 \mathrm{~d}$ vacancy decay via autoionizing channels is greatly suppressed for $\mathrm{Ce}^{3+}$ encapsulated inside a fullerene cage relative to free $\mathrm{Ce}^{3+}$.

Since the cage of the endohedral fullerene is transparent to the incident EUV photons, one has to conclude that most of the absorption oscillator strength of the $4 \mathrm{~d}$ electrons in the encapsulated $\mathrm{Ce}$ is diverted to decay channels other than net single and double ionization which were isolated and individually observed in the present experiment. It is hypothesized that the most likely additional decay channels for the relaxation of the $\mathrm{Ce}$ $4 \mathrm{~d}$ vacancy in the endohedral $\mathrm{Ce} @ \mathrm{C}_{82}^{+}$ions opened up by the presence of the fullerene cage are related to ionization with fragmentation. First evidence for this hypothesis was obtained by observing a $\mathrm{Ce} 4 \mathrm{~d}$ enhancement in the photo-ion yield of mass/charge separated $\mathrm{Ce} @ \mathrm{C}_{78}^{2+}$ produced from the parent $\mathrm{Ce} @ \mathrm{C}_{82}^{+}$beam.

In an attempt to quantify the $4 \mathrm{~d}$ suppression for single and double ionization of $\mathrm{Ce} @ \mathrm{C}_{82}^{+}$the cross sections for atomic $\mathrm{Ce}^{3+}$ ions were convoluted with a 5-eV gaussian which appears to give a reasonable representation of the smearing effect of the hybridization in the endohedral system. It turns out that $45 \%$ of the resulting convoluted cross section $\sigma_{3,4}$ gives a fairly good representation of the measured $4 \mathrm{~d}$ single ionization contribution in $\mathrm{Ce}_{0} \mathrm{C}_{82}^{+}$, which is well compatible with the overall $42 \%$ of 
the total absorption contribution. Trying the same with double ionization immediately shows that the measured 5-eV gaussian-convoluted cross section $\sigma_{3,5}$ (dotted curve in Fig. 3) contributes only $22 \%$ to the inferred Ce $4 d$ contribution to double-ionization of $\mathrm{Ce} @ \mathrm{C}_{82}^{+}$(shaded circles in Fig. 3). Reasonable agreement with the measured 4d doubleionization function is only obtained by including an additional $15 \%$ contribution of the 5-eV gaussian-convoluted cross section $\sigma_{3,4}$ (dashed curve in Fig. 3). This redistribution of partial oscillator strengths is a consequence of "post-decay" interactions of the ejected Auger electrons with the fullerene cage. Possibilities are electron scattering, electron capture, electron-impact ionization and fragmentation subsequent to ionization of the encapsulated $\mathrm{Ce}$ atom.

\section{SUMMARY}

In summary, clear spectral fingerprints of $4 \mathrm{~d}$ excitation of $\mathrm{Ce}$ atoms encapsulated in a fullerene have been observed both in single and double photoionization. For the first time, the anticipated redistribution of decay probabilities of a caged atom versus its free counterpart has been clearly demonstrated. Detailed energy-dependent information has been obtained on the effects of the electrons ejected from the encapsulated atom on the surrounding carbon sphere.

\section{ACKNOWLEDGMENTS}

This research was funded by the Office of Basic Energy Sciences of the U.S. Department of Energy and by the Deutsche Forschungsgemeinschaft.

\section{REFERENCES}

1. H. W. Kroto, J. R. Heath, S. C. O’Brien, R. F. Curl, and R. E. Smalley, Nature 318, 162 - 163 (1985).

2. Y. Chai, T. Cuo, C. Jin, R. E. Haufler, L. P. F. Chibante, J. Fure, L. Wang, J. M. Alford, and R. E. Smalley, J. Phys. Chem 95, $7564-7568$ (1991).

3. L. Dunsch, and S. Yang, Phys. Chem. Chem. Phys. 9, 3067 - 3081 (2007).

4. W. Harneit, C. Boehme, S. Schaefer, K. Huebener, K. Fostiropoulos, and K. Lips, Phys. Rev. Lett. 98, 216601 (2007).

5. M. A. G. Jones, J. J. L. Morton, R. A. Taylor, A. Ardavan, and G. A. D. Briggs, phys. stat. sol. (b) 243, $3037-3041(2006)$.

6. C.-Y. Shu, X.-Y. Ma, J.-F. Zhang, F. D. Corwin, J. H. Sim, E.-Y. Zhang, H. C. Dorn, H. W. Gibson, P. P. Fatouros, C.-R. Wang, and X.-H. Fang, Bioconjugate Chem. 19, 651 - 655 (2008).

7. K. B. Hartman, L. J. Wilson, and M. G. Rosenblum, Molecular Diagnosis \& Therapy 12, 1 (2008).

8. V. K. Dolmatov, Photoionization of Atoms Encaged in Spherical Fullerenes, Academic Press, 2009, chap. Theory of Confined Quantum Systems: Part Two Vol. 58, Advances in Quantum Chemistry, pp. $13-68$.

9. K. Mitsuke, T. Mori, J. Kou, Y. Haruyama, and Y. Kubozono, J. Chem. Phys. 122, 064304 (2005).

10. K. Mitsuke, T. Mori, J. Kou, Y. Haruyama, Y. Takabayashi, and Y. Kubozono, Int. J. Mass Spectrom. 243, $121-125$ (2005).

11. H. Katayanagi, B. P. Kafle, J. Kou, T. Mori, K. Mitsuke, Y. Takabayashi, E. Kuwahara, and Y. Kubozono, J. Quant. Spectrosc. Radiat. Transfer 109, 1590 - 1598 (2008).

12. M. Y. Amusia, J. Elec. Spectrosc. Rel. Phenom. 161, 112 - 120 (2007). 
13. A. Müller, S. Schippers, R. A. Phaneuf, M. Habibi, D. Esteves, J. C. Wang, A. L. D. Kilcoyne, A. Aguilar, S. Yang, and L. Dunsch, J. Phys.: Conf. Series 88, 012038 (2007).

14. A. Müller, S. Schippers, M. Habibi, D. Esteves, J. C. Wang, R. A. Phaneuf, A. L. D. Kilcoyne, A. Aguilar, and L. Dunsch, Phys. Rev. Lett. 101, 133001 (2008).

15. L. Dunsch, A. Bartl, P. Georgi, and P. Kuran, Synth. Met. 121, 1113 (2001).

16. P. Georgi, P. Kuran, and L. Dunsch, AIP Conf. Proc. 486, 106 - 110 (1999).

17. A. M. Covington, A. Aguilar, I. R. Covington, M. F. Gharaibeh, G. Hinojosa, C. A. Shirley, R. A. Phaneuf, I. Álvarez, C. Cisneros, I. Dominguez-Lopez, M. M. Sant'Anna, A. S. Schlachter, B. M. McLaughlin, and A. Dalgarno, Phys. Rev. A 66, 062710 (2002).

18. H. Kjeldsen, J. Phys. B 39, R325-R377 (2006).

19. W. Sato, K. Sueki, K. Kikuchi, K. Kobayashi, S. Suzuki, Y. Achiba, H. Nakahara, Y. O. F. Ambe, and K. Asai, J. Rad. Nuc. Chem. 239, 187-190 (1999).

20. K. Muthukumar, and J. A. Larsson, J. Phys. Chem. A 112, 1071 - 1075 (2008).

21. S. W. J. Scully, E. D. Emmons, M. F. Gharaibeh, R. A. Phaneuf, A. L. D. Kilcoyne, A. S. Schlachter, S. Schippers, A. Müller, H. S. Chakraborty, M. E. Madjet, and J. M. Rost, Phys. Rev. Lett. 94, 065503 (2005).

22. B. M. Henke, E. M. Gullikson, and J. C. Davis, At. Data Nucl. Data Tables 54, 181 - 342 (1993).

23. M. Habibi, D. A. Esteves, R. A. Phaneuf, A. L. D. Kilcoyne, A. Aguilar and C.Cisneros, Phys. Rev. A 80 (2009, in press).

24. Atomic and Optical Theory Group, Los Alamos National Laboratory (LANL) Atomic Physics Codes Package (available at http: //aphysics2.lanl.gov/cgi-bin/ION/runlanl08d.pl) 